\title{
Diagnosing Engineering Students' Competence of English Language Skills at Entry Level Academic Programme
}

\author{
Rajakumar Guduru ${ }^{1} \mathbf{8}(\mathrm{D}) \square$ and Ramya Devi Bommanaboina ${ }^{2}$ (D) \\ ${ }^{7}$ Assistant Professor, School of Humanities, Social Sciences and Management, Indian Institute of Technology, Bhubaneswar \\ ${ }^{2}$ Research Scholar, School of Humanities, Social Sciences and Management, Indian Institute of Technology, Bhubaneswar \\ Corresponding Author: Rajakumar Guduru, E-mail: rajakumarguduru@iitbbs.ac.in
}

ARTICLE INFORMATION ABSTRACT

Received: August 14, 2021

Accepted: September 20, 2021

Volume: 3

Issue: 9

DOI: $10.32996 /$ jhsss.2021.3.9.3

\section{KEYWORDS}

English Diagnostic test, competence, English language skills, remedial instruction
In the Indian context, an academic study program at the Indian Institutes of Technology (IITs) comprises a mixed group of learners coming from various socialeconomic, education, and a wide range of linguistic backgrounds. These learners secure admission into various engineering programs at IITs, having qualified for the Joint Entrance Exam (JEE), a national-level competitive exam. To qualify for this exam, students prepare rigorously, even at the school level. The JEE exam tests students' knowledge in the core subjects such as Physics, Chemistry, Mathematics, Aptitude and Reasoning; hence, students seem to focus more on these core subjects but not on the English language. These learners vary widely in their English language proficiency level in terms of oral and written English proficiency. It is believed that the level of language proficiency of learners has a direct influence on their academic performance in the program in which they are admitted. Therefore, the study aims at diagnosing 405 engineering students' competence of English language skills at the entry-level undergraduate engineering study programs of Bachelor of Technology at the Indian Institute of Technology, Bhubaneswar. A diagnostic test that comprised the components of English language skills was designed and administered to 405 students. The results were analyzed and interpreted qualitatively and quantitatively. It was found that the majority of the students who performed well in the test had better education backgrounds. For the students who performed poorly, the study recommends possible implications besides some remedial measures.

\section{Introduction}

The students who take admission into IITs comprise a mixed group of learners from various socio-economic and educational backgrounds. However, these learners are made to study and cope with the core courses with equal opportunities. Therefore, it is important to diagnose students' entry-level English language competence as they largely possess the intermediate level to advanced level of proficiency in the English language. In this regard, there is a need to understand learners' prior knowledge or background knowledge of English language skills so that the learners with less competence can be helped with some pedagogical and remedial measures for better academic performance. Such measures would help these learners raise their academic performance on par with their counterpart students who have advanced levels of proficiency in the English language. A diagnostic test is conducted prior to the actual teaching or learning. The primary focus of the diagnostic test is to pinpoint the learners' weaknesses, the attributes that the students have not yet fully mastered (Fan. T, 2021). Ofem, Idika, \& Ovat (2017) believed that the diagnostic testing is more concerned about students' weak areas in learning rather than the score that he/she obtained. Ugodulunwa (2008) referred to diagnostic testing as a process to check learners' background knowledge, skills, abilities, and perceptions. According to Hailikari; Ketterlin-Geller \& Yavanoff (2009), diagnostic assessment supplies specific

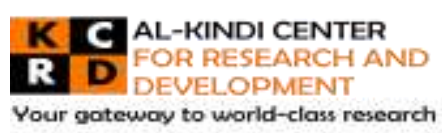

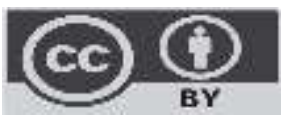

Published by Al-Kindi Center for Research and Development. Copyright (c) the author(s). This open access article is distributed under a Creative Commons Attribution (CC-BY) 4.0 license 
information on learners' learning inadequacies or incorrect prior learning. Hence, it can be concluded that the immediate attention of a diagnostic assessment is to identify learners' weak areas towards any subjects of learning (Zhao, 2013).

In his study, Alderson (2005) suggested certain characteristics of diagnostic assessment in teaching and learning as they are designed to identify gaps in a learner's knowledge and the use of language; focus on learners' weaknesses rather than on their strengths; give detailed feedback which furthers the effectiveness of learning and teaching; and lead to remediation in further instruction. It indicates that without a diagnosis of students' language skills, there is a high risk of drastically reducing their commitment to new learning (Highland Council of Education, Culture and Sport Services, 2010). Terwase and Oluwatoyin (2018) recommendations state that inclusion of diagnostic assessment in the learning process would improve students' comprehension, reduce their number of errors, and provide timely remediation measures. Perrin (2009) also opined that diagnostic assessment helps teachers plan their lessons appropriately and help struggling learners fill their gaps in language acquisition. According to Gani (2012), including diagnostic assessment in the curriculum increases learners' pass percentage and their performance in skill acquisition. It also helps in classifying students' levels of mastery and designing review activities.

From the opinions presented above, we can say that diagnostic test helps teachers and learners identify students' problems with the English language. Diagnostic test also informs teachers what areas of language need to be included in the syllabus. Generally, a diagnostic test consists of language skills components such as listening, speaking, reading and writing (LSRW), including questions on vocabulary and grammar.

\subsection{Significance of the Study}

Diagnostic tests play a significant role in English language learning because they reveal both weak and strong areas of a language learner. The diagnostic test given at the beginning of the year or semester or course can help a teacher plan the instruction effectively, know how much the students have learned so far, and what concepts to re-taught. For instructors who want to provide target-oriented instruction, an effective diagnostic assessment instrument is essential (Qin Xie, 2020). Overall, a diagnostic test can help the student to know how much the student has grown linguistically or in the knowledge of a subject (Natasa and Mirjana, 2019).

Students studying at engineering colleges and institutes come from various socio-linguistic backgrounds. These students' English language proficiency ranges from intermediate level to advanced level. Hence, a diagnostic test has been designed to evaluate and analyze individual learners' competence in English language skills. The diagnostic test is significant in a way to enquire into the difficulties of students in the English language so that appropriate remedial measures can be applied. Similarly, this study can help English language teachers and other practitioners understand the issues related to English language skills at the entry-level of college-level study at IITs in India. This would help the teachers know and make appropriate decisions regarding the assessment of learners' English language skills, which will be useful to adopt alternative methods of instruction and learners to improve their academic success. Thus, diagnosing learners' difficulties is of great use in making teaching and learning more effective.

\subsection{The Aim and Objectives}

The main aim of the study is to diagnose students' entry-level of competence of English language skills. The objectives of the study are to -

- $\quad$ identify students' strengths and weaknesses in English language skills performance.

- $\quad k n o w$ if the students' present skills would help them on academic performance of the undergraduate study program.

- $\quad$ know students' prior knowledge or background knowledge of English language skills.

\section{Literature Review}

The traditional method of classroom assessment is mostly administered at the end of an instructional period to assess learning outcomes (Zhao, 2013), whereas diagnostic test can be seen as the reversal of it because it mainly focuses on what has gone wrong with the learner's learning process (Mousavi, 2000). Patricia et al. (2020) opined that student's individual efforts in the academic field are assessed through testing. The most commonly used testing processes to measure and validate students' learning progress are formative, summative, and diagnostic testing. However, the purpose of diagnostic testing varies from other assessments as its interest mostly lies in failure rather than what is achieved.

Natasa and Mirjana (2019) deployed the diagnostic assessment in an English language classroom to know the students' level of performance during English language courses at the University of Prigtina's Faculty of Philosophy in Kosovska Mitrovica. The main purpose of this test is to help teachers being aware of their students' English language skills and the areas where students need to work on during the course. Sewell (2004) also employed a diagnostic test for the adult learners of the United Kingdom to provide feedback on the skills and aptitudes of learners. To realize this purpose, he developed various tasks that included 
both multiple choices and open writing tasks. The research results found out that diagnostic tests provided comprehensive feedback on learners' strengths and weaknesses.

The empirical evidence gathered by Jang's (2005) study showed that the effects of the diagnostic test were quite valid and could provide rich feedback to teachers and students for their intrinsic growth. The researcher also proposed a customized diagnostic assessment framework as an alternative approach to formative, diagnostic assessment. Furthermore, another study on the development and validation of a diagnostic test was conducted by Richards (2008). The research results showed that the test could provide useful feedback to the learners about the areas that need to be improved.

Bakic (2012) opined that diagnostic tests could be especially beneficial for teachers who have multiple classes to teach within one subject. This is the case in the English for Specific Purposes course at the University of Niš Medical School. There are three study groups: pharmacy, registered nursing, and associate nursing degree. The diagnostic test conducted by the researcher showed that pharmacy students are comfortable with communication in English, registered nursing students are not, while associate nursing degree students still need some practice in that area. An important part of English language teachers' expertise includes understanding assessment principles and procedures more thoroughly. The teacher should identify a few areas on which they feel the student could realistically work and achieve a significant improvement in their English. For instance, in the case of junior year RNS students, understanding, reading and translating medical texts, in the case of associate nursing degree students, further improvement of communication skills for presentation purposes and in case of pharmacy students, communication practice and implementation of grammar rules in speaking and writing.

\section{Methodology \\ 3.1 Participants}

405 ESL students (male=329; female=76) participated in the study. These are entry-level students of an engineering undergraduate programme at one of India's national importance institutes. These learners will major in various engineering subjects to obtain a bachelor's degree in engineering. These learners come from various states of India, therefore, have various levels of competence in English. English diagnostic was administered to all the learners to identify their current competence level as well as background knowledge of English language skills.

\subsection{English Diagnostic Test}

English Diagnostic Test for the entry level B.Tech students were designed and conducted. The total number of students is 405 and all students have participated in the test. English Diagnostic Test was designed for 100 marks which mainly consisted of three parts: Part - A: Grammar, Vocabulary, Reading comprehension, and Listening comprehension (Objective in nature with multiple choices, 60 marks); Part - B: Writing Skills (descriptive in nature, 20 marks); and Part - C: Speaking Skills (20 marks).

Questions on language components such as grammar, vocabulary, reading comprehension, and listening comprehension were objective in nature with four multiple choices. Answers to these questions have to be marked on the OMR answer sheet. After completion of the objective questions, a writing task which was descriptive in nature was conducted. Students had to provide answers to questions on the answer sheet provided. The questions given for the writing task have specific expectations about the way in which students structure their responses. However, maintaining the structure and organization, students are free to put their ideas together in a manner they feel best fulfills the requirements of the task. In the process, students were advised to stick to the word limit so that the answers could be more precise and more focused.

All the students were given required instructions before the beginning of the test. All sections were timed, and accordingly, students were advised to maintain the time limit for each section. Listening comprehension was tested first and each audio track was played only twice. The rest of the components of the test were answered by the students within the given time. The OMRbased objective test was evaluated mechanically by running the software to obtain quick and accurate results. The answer scripts of the written test were manually evaluated by 14 language experts who belong to various reputed institutes/universities in India. As the number of students is too large, a speaking skills test was conducted for individual students by the same 14 language expert-teachers. Speaking skills of each of the students were assessed for about ten minutes using two speaking tasks. All the scores of speaking, writing and objective test were compiled and the total marks was obtained.

\subsection{Data Analysis and Interpretation}

The data have been analyzed and interpreted qualitatively by thickly describing the results. The results have been organized along the language components tested in a diagnostic test. 
Figure 1: Diagnostic test results

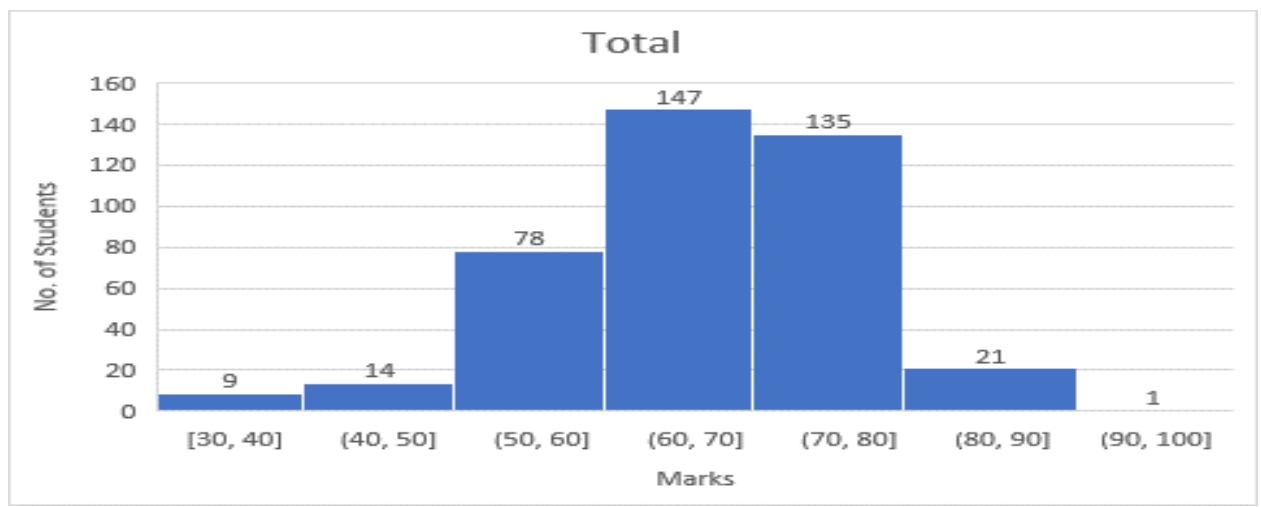

The total number of students who participated in the test was 405 . The graph above shows that 1 out of 405 students i.e., $0.2 \%$ scored above 91 marks. And the number increases to 21 students i.e., 5.18\% who scored between 81 and 90 marks. There's a consistent increase in the number to 135 students i.e., $33.33 \%$ who scored between 71 and 80 marks. There's a slight decrease in the number to 147 students i.e., $36.29 \%$ who scored between 61 and 70 marks. The number has further decreased to 78 students i.e., $19.25 \%$ who scored between 51 and 60 marks. The number has further decreased to 14 students i.e., $3.45 \%$ who scored between 41 and 50 marks. The number has further decreased to 9 students i.e., $2.22 \%$ who scored between 31 and 40 marks.

Overall, the skills and language performance is shown by the majority of students were impressive. Furthermore, a good number of 303 students $(74.81 \%)$ responded well and presented their ideas meaningfully on the speaking test. The same group of students also performed well on the objective test and the written part of the test, demonstrating their understanding of the knowledge and skills in English. The students who scored marks 61 and above (74.81\%) could be grouped under the 'Good Excellent' range. The rest of the 101 students (24.93\%) who scored marks 60 and below could be grouped under the 'Average Poor' range. Some of the reasons for their poor performance on the test were these students studied in vernacular medium schools, had less educated parents, and had less exposure to learning resources. From the teachers' observations, the reasons were quite evident that these students come from English medium schools having the support of the educated parents and good exposure and availability of resources, etc.

\section{Objective Test - Grammar, Vocabulary, Listening and Reading Comprehension}

Students were tested on 30 objective-type questions on grammar and vocabulary with multiple choices (A, B, C, D). Students had to read and choose the correct option from the given choices. On the listening task, as they listened to the topic Talk on Eden Project and TV news report students had to choose the correct answer for each item from the given choices. The listening task was administered for 20 minutes for 15 marks. The audio was played only twice. Two short reading passages were given to test students' reading comprehension skills. As students read the passages, they had to choose the correct option for every 15 items from the choices given within 30 minutes.

Figure 2: Students' score in Objective Test - Grammar, Vocabulary, Listening and Reading Comprehension

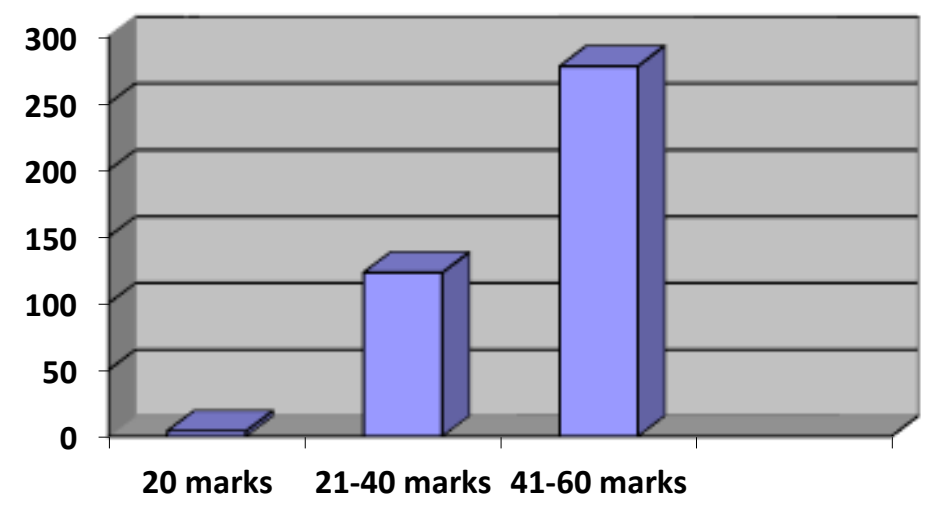

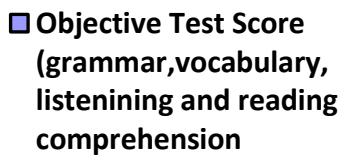

口Objective Test Score (grammar,vocabulary, listenining and reading comprehension

The above diagram shows that only 4 students (0.98\%) scored 20 marks and below, indicating that these learners have lower intermediate proficiency in English grammar, vocabulary, listening, and reading comprehension skills. As many as 123 students (30.3\%) scored between 21-40 marks, indicating the intermediate level of proficiency of these learners in English grammar, 
vocabulary, listening, and reading comprehension skills. A large number of 278 students (68.6\%) scored between 41-60 marks and it shows that these learners have upper-intermediate proficiency in grammar, vocabulary, listening, and reading comprehension skills.

\section{Writing Skills}

A writing task 'a three-body paragraph essay' on one of the two topics, 1. Impact of smart phones on the present generation students. 2. The advantages of reading a newspaper every day were given to students for about 350-400 words. Students' score on the writing task is presented below.

Figure 3: Students' score on Writing task

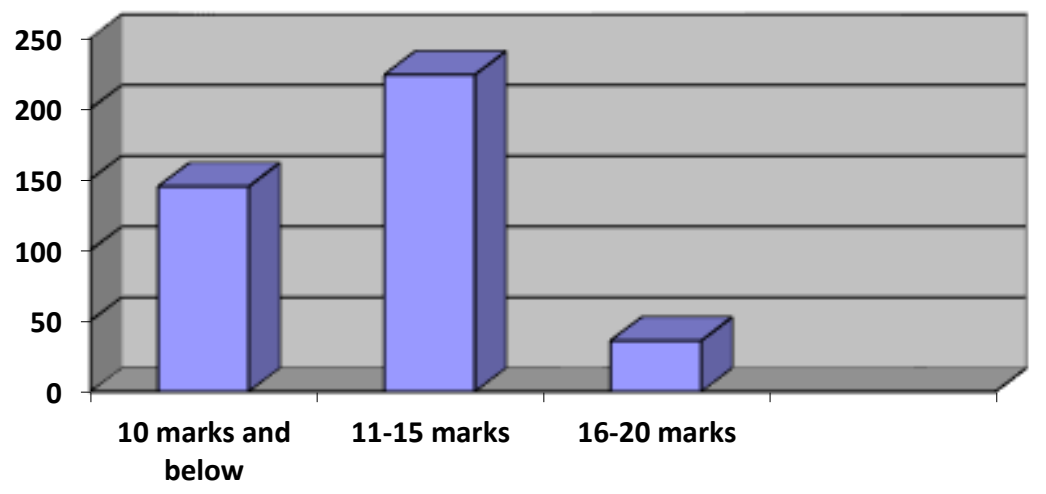

口Writing

From the analysis of the results as presented in figure 1 above, it was observed that 36 students (8.8\%) who scored 16 marks and above have reasonably good command over writing which is nearly error-free. 224 students (55.3\%) who scored between 11 and 15 marks seem to be misusing punctuation, articles and prepositions in their writing. 145 students (35.8\%) who scored 10 marks and below seem to be weak in writing. Their writing can be considered poor as it has issues such as - run-on sentences, lack of expressing ideas and organizing them coherently, subject-verb agreement, incomplete sentences, use of punctuation, grammatical errors inappropriate usage of words, spelling mistakes. They do not seem to know sentence formation, task format, collocations, and paraphrasing of the topic.

\section{Speaking Skills}

To test students' speaking skills, they were given two tasks. Task 1: Common Introductory Frame contained 10 questions, of which at least five questions were asked before moving on to Task 2. Task 1 was timed for two minutes. To ensure uniformity, the questions were not rephrased unless absolutely necessary for the purpose of comprehension and clarity. Task 2: Cue Cards After at least (any) five questions from Task 1 are covered, a copy of a single task 2 and two cue cards are given to the candidate. The candidate should be informed in advance that they can take a maximum of one minute to prepare notes/scribbles for a twominute speech. The activity was timed accordingly (one-minute preparation and two minutes of speaking). After the task, few follow-up questions related to the topic were asked. Overall, students' speaking skills were tested based on the four parameters: fluency and coherence, lexical resource, grammatical range and accuracy, and pronunciation. Students' score on speaking task is presented below.

Figure 4: Students' score on Speaking tasks

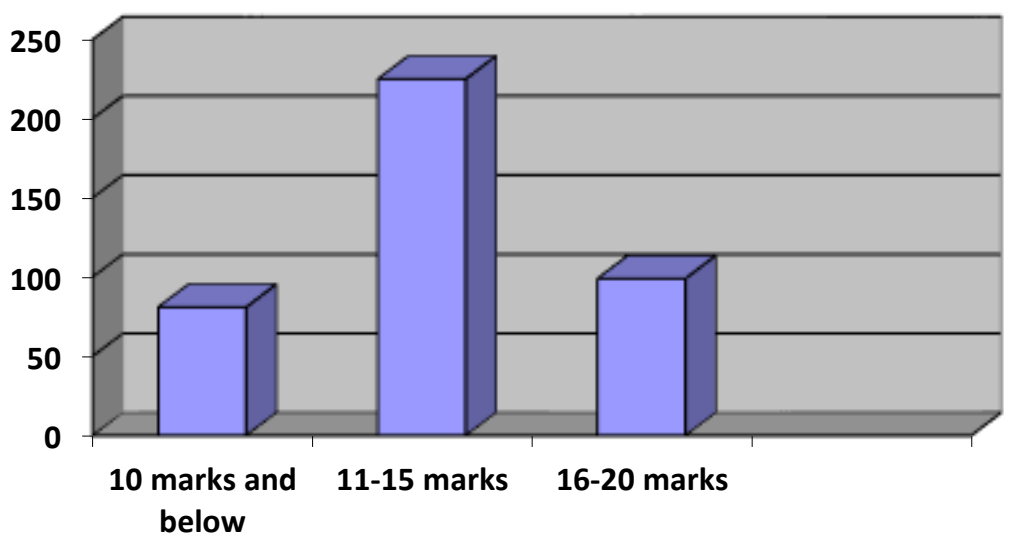


From the task analysis of speaking skills, it can be observed that 81 students (20\%) scored between $0-10$ marks. These students exhibited poor communication skills and frequently switched over to their vernacular language. They did not seem to understand the instructions given. Their speech is full of grammatical errors and improper sentence structure. Their speech consisted of broken words lacking confidence. The majority of the 225 students (55.5\%) scored between 11-15 marks. These students have a good command of language but need to work on body language, vocabulary and accent. As many as 99 students (24.4\%) scored between 16-20 marks out of 30. This high score indicates their excellent command over the content. They are good at idea generation and maintained clarity in articulating their ideas. They also exhibited confidence while speaking and had complete eye contact with the audience.

During the implementation of the test, it was observed that students were able to adjust to the practical constraints with very little difficulty. On the other hand, it was observed that some students did not fully engage in the test due to some practical problems like seating arrangements, congested ambience, etc. Some students were quite nervous during the speaking test, but they were calmed with enough care and attention. Some students could not manage the time allotted for each section as a result. They could not attempt all objective-type questions. The majority of the students did not plan and organize their thoughts while writing the answers to questions. As a result, some students produced answers without any organization and direction, which are essential requirements of the writing task. Students who showed confidence in analyzing the thought process and presenting the language forms scored high marks.

\section{Results and Discussion}

The main aim of this study was to identify students' issues in English language skills and performance; in addition, it is also an attempt to know the entry-level of competence and prior knowledge or background knowledge of students' English language skills.

In most cases, it was found that there is a close relationship between the students' high performance on the test and the educational background they came from. In other words, students who had a good parental educational background and better schooling performed well in the test. Those students who scored fewer marks on the test mostly come from the regional medium schools and colleges and have poor educational backgrounds. As per the performance in the test, it was found that students who scored high marks in the objective part of the test (grammar, vocabulary, listening, and reading comprehension) also scored high marks in the subjective part of the test (speaking and writing skills). Therefore, it can be said that students' high performance in English language skills in the test could be attributed to their background education.

The combined test score (see figure 1) obtained by the students shows that out of 405 students 303 students scored high between 61-100 marks on the test. It was found that these learners have done well on both the objective and subjective parts of the test by exhibiting the attributes such as conversation strategies (gestures, eye contact, voice, pitch, volume), presentation skills, content organization, grammatical accuracy, use of appropriate vocabulary, fluency, pronunciation, clarity, and listening for main ideas and listening for more details. These learners also have shown up adequate competence in the descriptive part of the test by presenting the language elements required for writing such as grammar of sentences, punctuation, logical sequence, unity and coherence, vocabulary usage, essay and letter structure, presentation of ideas, handwriting, and spellings.

From the data analysis, it is observed that female students have performed better than most of the male students. It supports a general view that female students are good at English language skills. Although students (405 students) belong to one of the institutes, they represent the overall education scenario in India as these learners come from various states of India. As we can see that most of the students (303) have performed well in the test, we can say that these learners have the English language competence required at the entry-level of a new study program. Hence, an advanced-level course in the English language was offered to all the students who scored high marks. It is assumed that students' current language competence would help them in the academic performance of the undergraduate study program.

The students who scored average and poor marks in the test were offered an intermediate-level course to improve their English language competence. These learners were also recommended for doing a remedial course for additional help and support. The researcher's experience shows that these learners need a personal study to improve their English language skills with the advanced students.

The following recommendations may be considered to help students improve their gaps/weaknesses in English language skills. There may be a special initiative by the institute to offer remedial classes to weak students to improve their language skills. Faculty advisors of these students may monitor their improvement in language skills by encouraging them to participate in various activities. Parents may be informed about learners' performance on the test to motivate their children. Students may take advantage of online resources available plenty for improving their English language skills such as functional grammar, communication skills, reading comprehension, listening skills, and vocabulary. Students should take the personal initiative to read 
widely on various topics of interest to improve their vocabulary knowledge. Most importantly, it is beneficial for students if the teaching methodology and the implementation of the curriculum at the Institute is tailor-made to suit the entry-level skills and knowledge of students admitted into a program.

\section{Conclusion and Implications for Teaching}

In view of the findings of this study, some of the implications are as follows. First, from the findings of this study, it is hoped that educators can see the relevance of diagnostic testing in teaching and learning and may apply it at the beginning of every new academic program. Second, educators need to detect students' basic knowledge before teaching them the new content as it allows educators to understand the current state of their students' knowledge and plan intervention strategies in their teaching to deal with the issue. Third, it is believed that integrating diagnostic assessment in the teaching and learning process would improve students' comprehension level, reduces their errors, misconceptions and provide timely mediation measures in achieving learning outcomes. It would also lead to a reduction in the failure rate in the standardized examinations and improve the quality of education in the country in general. Next, teachers should be provided with adequate training on conducting, designing, and implementing diagnostic assessments according to the set standards. Further, seminars and workshops should be organized to sensitize teachers on the importance of diagnostic assessment in the teaching and learning process.

Most importantly, students should be provided with writing scores with sufficient descriptions and feedback on scores to improve their writing. Feedback provided by diagnostic tests can be used to improve language teaching and learning. Finally, we recommend gathering more literature review of the studies exploring the effectiveness of different diagnostic tests at various levels of academic programs. Such information would facilitate teachers with a better idea of how to design and teach a remedial course. With the rapid development of new technologies, diagnostic tests may be conducted online for quick and accurate results.

The study has attempted to diagnose engineering students' English language skills competence at the entry-level of an academic program. It has presented students' strengths and weaknesses, current knowledge and skills, and also prior knowledge of the English language. As this study shows, there are both high level and low-level performers in the test as per their respective academic backgrounds they came from. Therefore, teachers need to note these differences related to English language performance and skills to help them fix the issues identified. This study has presented the results as per the students' performance on the diagnostic test. To validate these results, requires further testing of students in the English language skills over time. Hence, we believe that further research in diagnosing the entry-level competency in English language skills of engineering students studying at other premier institutions and universities is necessary.

\section{Acknowledgements}

We would like to thank Prof. R.V. Raja Kumar, Director of the Indian Institute of Technology, Bhubaneswar, for conducting this study's educational initiative and motivation. Special thanks to Prof. V. R. Peddireddi, Dean of Student Affairs; Prof. Pravas Ranjan Sahu, Dean Academic Affairs; and Prof. Swarup Kumar Mahapatra, Head, School of Humanities, Social Sciences and Management, for their invaluable support and encouragement. Finally, we would like to express our appreciation and thanks to our student participants in the study.

\section{References}

[1] Alderson, J. C. (2005). Diagnosing foreign language proficiency: the interface between learning and assessment. London: Continuum.

[2] Fan, T., Song, J. \& Guan, Z. (2021). Integrating diagnostic assessment into curriculum: a theoretical framework and teaching practices. Lang Testing in Asia, 11(2). https://doi.org/10.1186/s40468-020-00117-y

[3] Gani, P. S. (2012). Diagnostic assessment of senior secondary two students' achievement in quantitative aspect of Economics in Akwanga Educational Zone, Nasarawa state. Unpublished M.Ed. thesis. Department of Educational Foundations, University of Jos.

[4] Hailikari, T. (2009). Assessing university students' prior knowledge: Implications for theory and practice. University of Helsinki. http://urn.fi/URN:ISBN:978-952-10-5946-9

[5] Highland Council of Education, Culture and Sport Services. (2010). Diagnostic assessment. Retrieved from www.keyskillssupport.net/teaching/assessment/

[6] Jang, E. E. (2005). A validity narrative: Effects of reading skills diagnosis on teaching and learning in the context of NG TOEFL. Unpublished doctoral dissertation, University of Illinois at Urbana-Champaign.

[7] Ketterlin-Geller, R., \& Yovanoff, P. (2009). Diagnostic assessment in mathematics to support instructional decision making. Practical Assessment, Research and Evaluation, 14(16), 2.

[8] Kunnan, A. J., \& Jang, E. E. (2011). Diagnostic feedback in language assessment. In Long, M., and Doughty, C. (Eds.), Handbook of second and foreign language teaching. Walden, MA: Wiley-Blackwell Publishers.

[9] Lee, Yong-Won. (2015). Future of diagnostic language assessment. Language Testing. 32, 295-298. 10.1177/0265532214565385.

[10] Mousavi S. A. (2012). An Encyclopedic Dictionary of Language Testing (5th edition). Tehran: Rahnama Press

[11] Some implications for using a diagnostic test in English language courses at post-secondary level. January 2019. DOI:10.5937/ZRFFP49-20409. Natasa Bakic-Miric. Mirjana Lončar-Vujnović 
[12] Ofem, U. J., Idika, D. O., \& Ovat, S. V. (2017). Effect of Diagnostic and Feedback Assessment Approaches in Enhancing Achievement in Mathematics among Secondary School Students in Calabar Municipality. International Journal of Scientific Research in Education, 10(2), 221-227.

[13] Nkechi Patricia-Mary Esomonu, \& Lydia ljeoma Eleje. (2020). Effect of Diagnostic Testing on Students' Achievement in Secondary School Quantitative Economics doi:10.5430/wje.v10n3p178 URL: https://doi.org/10.5430/wje.v10n3p178

[14] Perrin, G. (2009). Diagnostic procedures in English language teaching. Modern English Teacher. 18(1), 49-54.

[15] Qin Xie. (2020). Diagnosing Linguistic Problems in English Academic Writing of University Students: An Item Bank Approach. Language Assessment Quarterly, 17(2), 183-203. DOI: 10.1080/15434303.2019.1691214

[16] Richards, B. J. (2008). Formative assessment in teacher education: The development of a diagnostic language test for trainee teachers of German. British Journal of Educational Studies, 56(2), 184-204. https://doi.org/10.1111/j.1467-8527.00403.x

[17] Sewell, J. (2004). Diagnostic assessment within skills for life strategy. Paper presented at the International Association for Educational Assessment, Philadelphia.

[18] Targema, Numbe Terwase and Oluwatoyin C. Obadare-Akpata (2018). Diagnostic Assessment: A Tool for Quality Control in Education. Journal of Educational Research and Review, Vol. 1, 17-24.

[19] Ugodulunwa, C. A. (2008). Fundamentals of educational measurement and evaluation. Jos: Fab Educational Books.

[20] Zahra Shahsavar, \& Mustafa Asil (Reviewing editor). (2019) Diagnosing English learners' writing skills: A cognitive diagnostic modeling study. Cogent Education, 6:1, DOI: 10.1080/2331186X.2019.1608007

[21] Zhao, Zhongbao. (2013). An Overview of Studies on Diagnostic Testing and its Implications for the Development of Diagnostic Speaking Test. International Journal of English Linguistics. 3. 10.5539/ijel.v3n1p41. 